\title{
Thermal modelling and thermography measurements of thermoregulation effects in a skin tissue
}

by M. Strąkowska, M. Strzelecki, B. Więcek

Lodz University of Technology, Institute of Electronics, 211/215 Wolczanska St. 90-924 Lodz, Poland, maria.strakowska@p.lodz.pl

\begin{abstract}
The aim of this research was to develop a local thermal model of human skin including thermoregulation effects. It was shown that the thermoregulation is associated with the negative thermal feedback in an alive organism. In this paper we present the experimental and modelling results of temperature recovery after weak and deep thermal provocation. The results of the research confirm that the thermal feedback corresponds to the variation of perfusion coefficient in the well-known, frequently used Pennes thermal model of a tissue.
\end{abstract}

\section{Introduction}

Thermoregulation in the alive tissues is an interesting scientific problem, known for years which can be used in medical practice $[10,11,12,13]$. Due to the strong dependence between the thermoregulation and some pathologies of a tissue, modelling of thermoregulation together with thermal measurements using thermography can be applied for developing new screening protocols [14]. Thermoregulation and its modelling are very actual topic in medical and technical research $[1-13,16]$. In most of publications, the problem of thermoregulation is treated globally, for the whole human body to estimate the mean body temperature and the thermal comfort [13]. The thermoregulation in a tissue has to take into account both the environmental (external) and internal tissue parameters [1,2,3,12]. Mathematically, it is a complex problem which includes shivering, sweating and vasomotion (vasoconstriction and vasodilatation) [11,13]. In many cases it was simplified and successfully verified by the experiments $[10,13]$. One of the most popular and widely accepted reference thermoregulation model of human body uses the Universal Thermal Climate Index (UTCl) to predict the body core and local skin temperature in different environmental conditions [10]. Most of the thermoregulatory models are based on multi-node structures $[1,2,12,13]$. Originally the models consisted of few hundreds nodes and they were successfully simplified to dozens ones, including head, face, neck, thorax, abdomen, shoulders and extremities: arms, hands, legs and feet. Each organ is modelled by cylindrical or spherical multilayer structure [13]. The convection and radiation heat transfer were applied for heat balance of a body both for indoor and outdoor ambient conditions [2]. An interesting assumption of Fiala's model is that the long wavelength radiation models the cooling, while the short wavelength is applied for heating $[2,3,13]$.

In this paper we contributed to the local thermoregulatory modelling for a skin tissue. By applying weak and deep thermal stresses, one confirmed that thermoregulation in a skin tissue can be explained as linear (in the first approximation) and nonlinear thermal feedback (for more advanced analysis). 


\section{A new method of thermoregulation modelling in a tissue}

At the beginning of this research it was assumed that thermoregulation and perfusion are correlated with each other. The simple basic scenario to induce the thermoregulation and in consequence to change the blood flow, is the heating or cooling a skin tissue with different strength. The body reaction seems to be similar to a close loop feedback system (Thermoregulation Feedback Model - TFM) as it is shown in fig. 1. It assumes that a tissue is mathematically described by its thermal impedance $Z_{\text {th }}[15,17]$. Thermal impedance can be presented in different forms, e.g.: in Laplace domain by the Nyquist plot and as R-C Foster or Cauer networks [17]. It has been already proven, that thermal impedance of a tissue varies for different power excitations [16]. Changing the excitation of a tissue from "weak" to "deep" should result in varying the value of the feedback coefficient $\beta$ in the proposed model - fig. 1 .

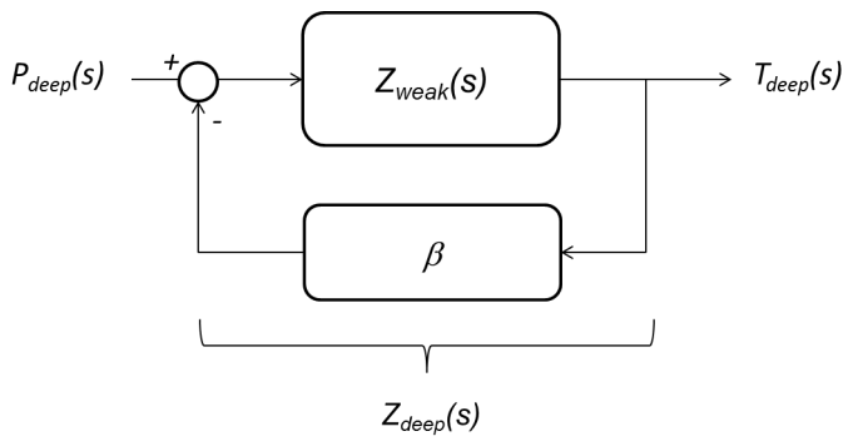

Fig. 1: Concept of Thermoregulation Feedback Model (TFM) of a tissue

The goal of the research was to verify the hypothesis that the feedback coefficient $\beta$ correlates with the perfusion coefficient of the Pennes model, frequently used in thermal investigations of biomedical objects. The perfusion coefficient was estimated by previously developed method using multilayer thermal modelling of a tissue based on the Pennes equation in frequency domain $[14,15]$.

In order to estimate the feedback coefficient $\beta$, an optimisation algorithm was proposed - fig. 2. Two sets of experimental data (temperature vs. time) from weak and deep provocations were transformed to the discrete time constant distribution using Thermal Object Identification - TO/methodology [17]. Next, the model from fig. 1 was trimmed by changing $\beta$ to get the impedance of deep cooling $Z_{\text {thdeep }}$ assuming that the thermal impedance of the weak cooling experiment $Z_{\text {thweak }}$ is in the main path of the system in fig. 1 . As the result, one gets the estimated feedback coefficient $\beta$. At last, the feedback coefficient $\beta$ is compared with perfusion coefficient from the Pennes model of the skin previously fitted to the experimental data. $[14,15]$. 


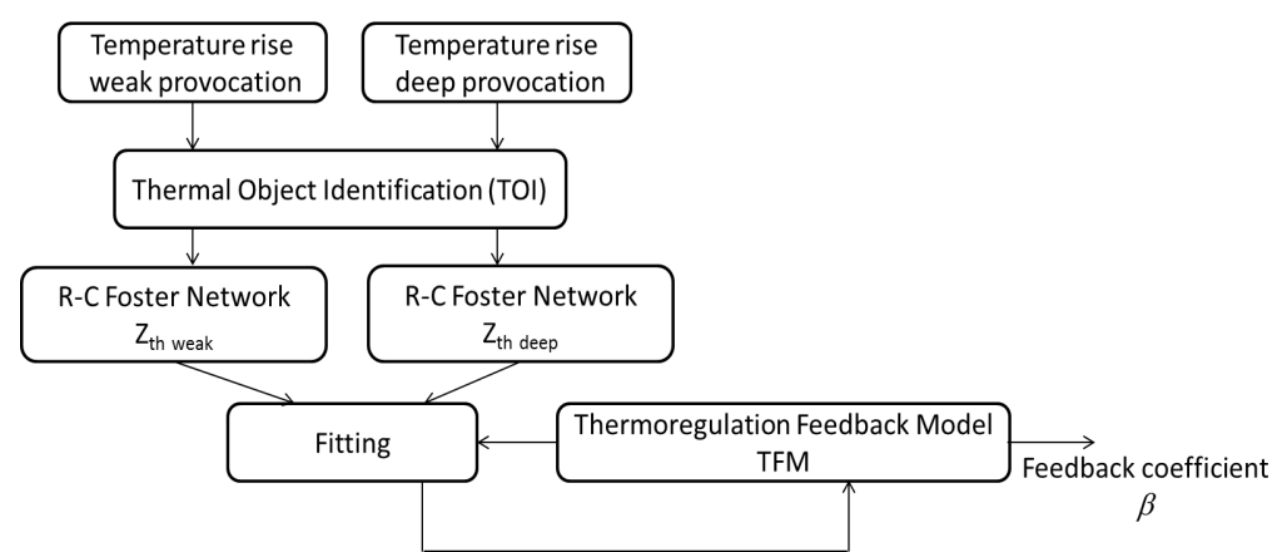

Fig. 2: A concept of estimating coefficient $\beta$ of Thermoregulation Feedback Model

\section{Thermographic measurements}

The healthy subject (a volunteer) agreed for cooling down the small area of the skin on the back using 2 metal blocks. The metal blocks were cooled down to 2 different temperatures $\left(5\right.$ and $\left.-20^{\circ} \mathrm{C}\right)$. The blocks were attached to the skin for about $5 \mathrm{~s}$. - fig. 3. Immediately after removing the cooling devices, temperature rise was measured and recorded by a quantum photon IR camera. The camera parameters were: $N E T D=15 \mathrm{mK}$ at the frame rate $f_{\text {cam }}=50 \mathrm{~Hz}$. The correction of the patient's movement was necessary to use before the further analysis.

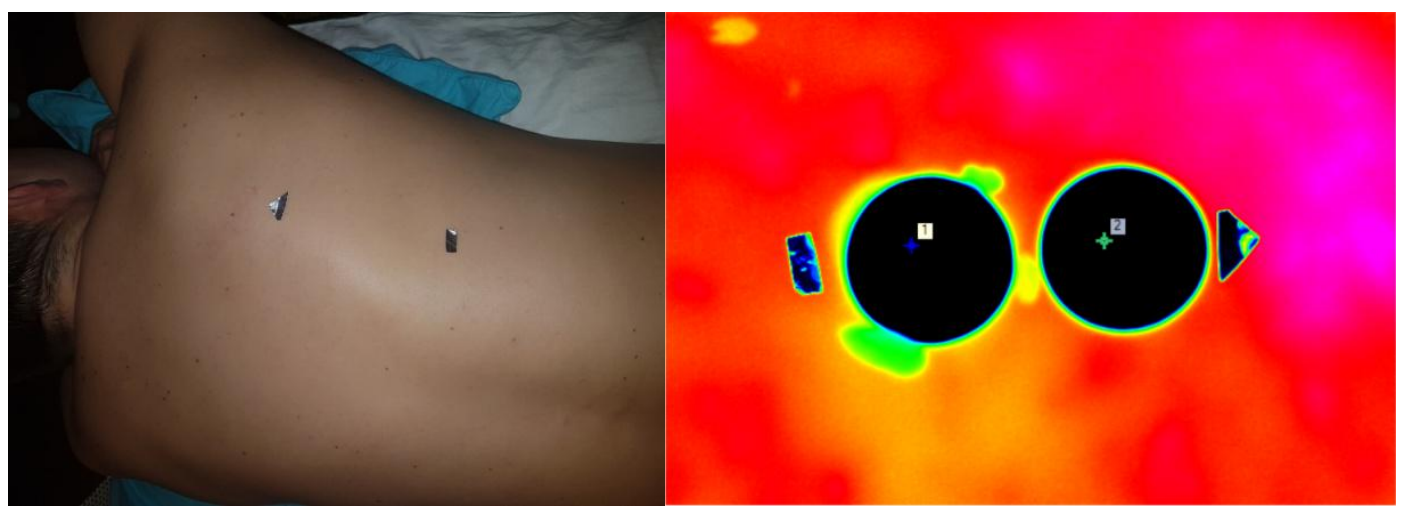

Fig. 3: Two regions of the skin on the back of the healthy volunteer, cooled down for $5 \mathrm{~s}$ by cold metal blocks in different initial temperature, left $-20^{\circ} \mathrm{C}$ (deep cooling), right $+5^{\circ} \mathrm{C}$ (weak cooling) 


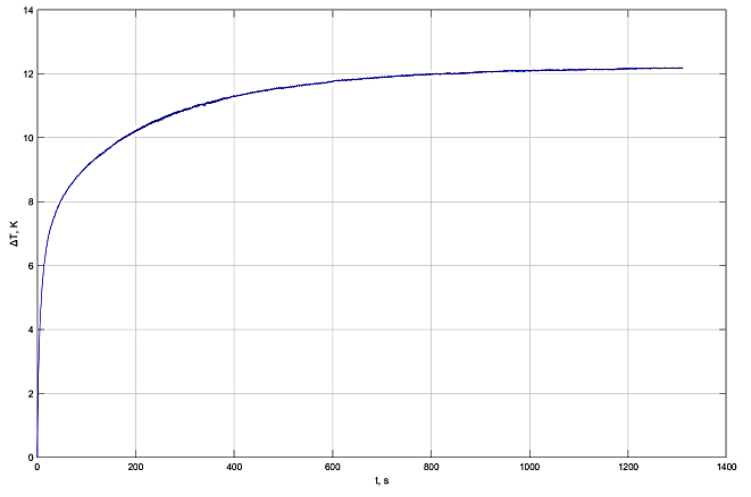

a)

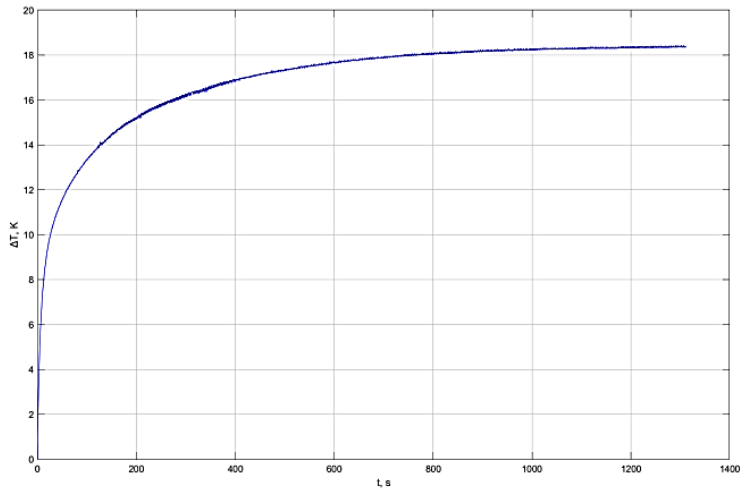

b)

Fig. 4: Temperature rise of the skin after removing the coolant for a) weak and b) deep cooling

Temperature recovery after patient's body movement is shown in fig.4. Temperature was normalized to start from zero for both cases: weak and deep cooling. Deeper cooling causes the higher temperature variation by about $6^{\circ} \mathrm{C}$. The sequence of thousands of thermal images was recorded during the session lasting more than 20 min.

\section{The analysis using $R-C$ Fosterand Cauerthermal network approximations}

Using the Thermal Object Identification (TOI) protocol, the analysis was performed in the frequency domain [17]. In consequence, the skin as a multilayer thermal bio-structure can be modelled by $R-C$ thermal ladder, either as the Foster or Cauernetwork [17]. The results of thermal approximation of the model by the 4-time constants networks are presented in figs $5-6$.
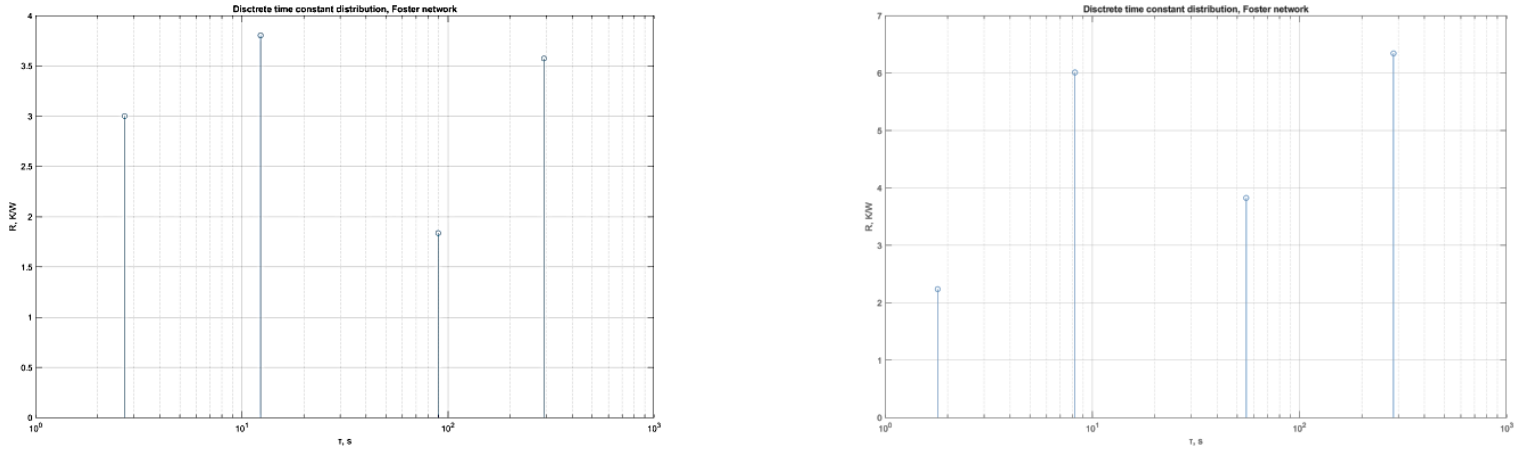

Fig. 5: Discrete thermal time constants distribution for 2 regions of the skin with a) weak and b) deep cooling
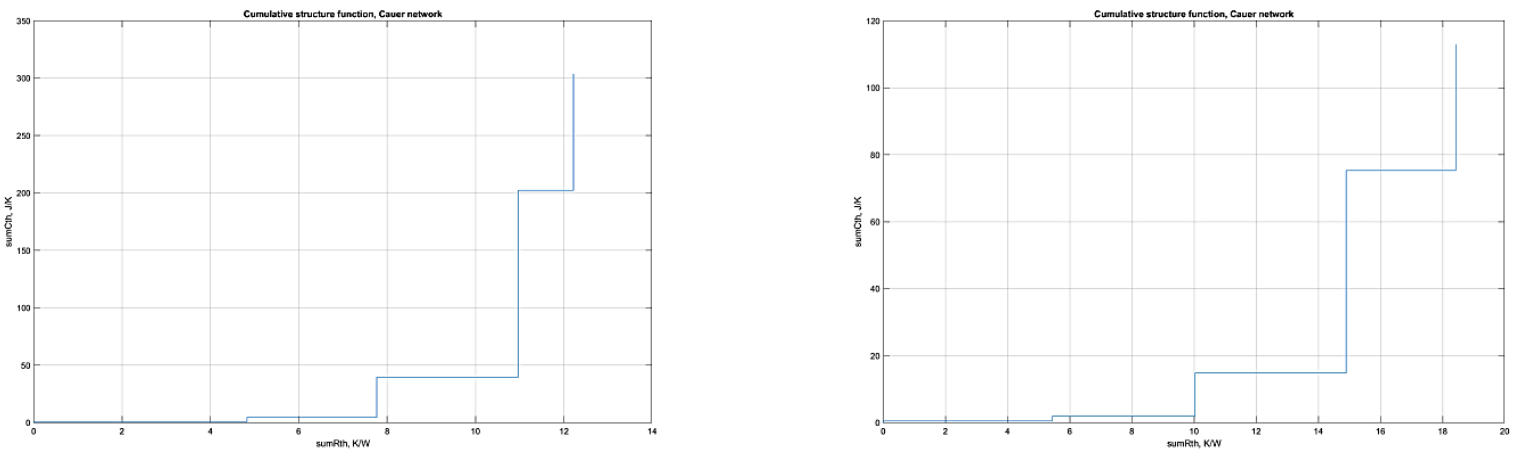
Fig. 6: Cumulative structure functions for 2 regions of the skin with a) weak and b) deep cooling

In order to confirm the correctness of results obtained using the TOI methodology, the original and approximated temperature during heating the skin were compared - fig. 7. As one see, agreement between temperatures in the experiment and approximated by $R-C$ Foster network is quite satisfactory.
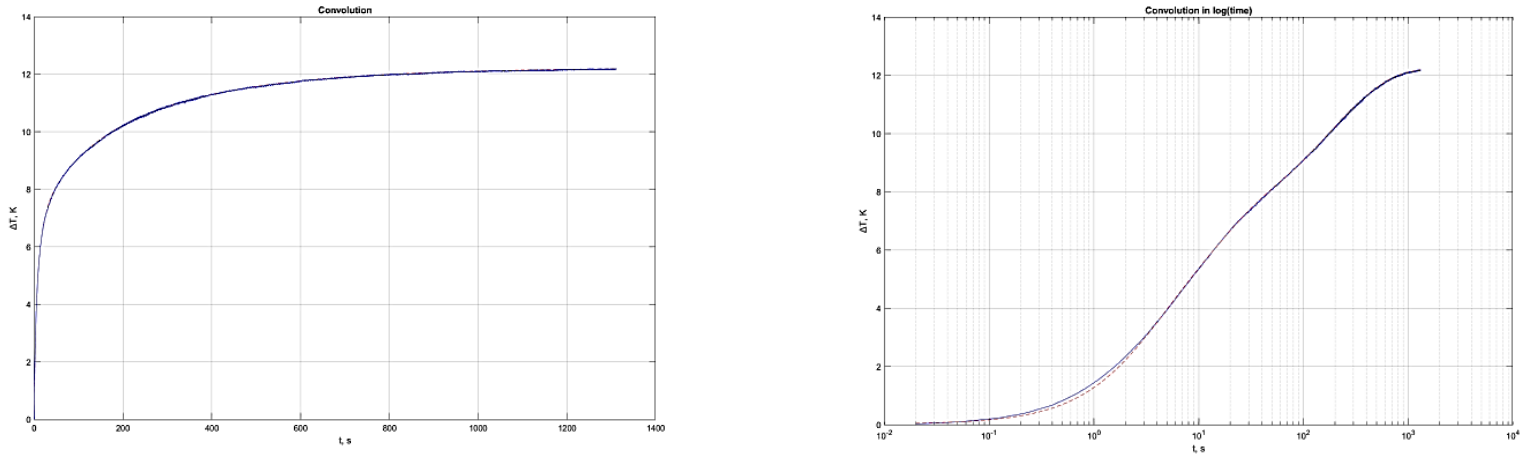

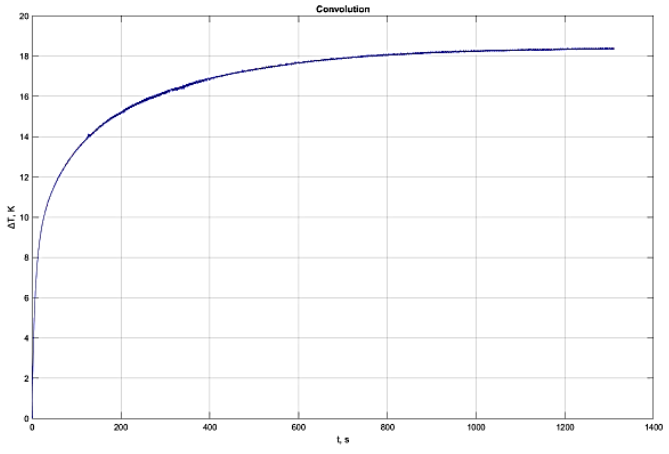

a)

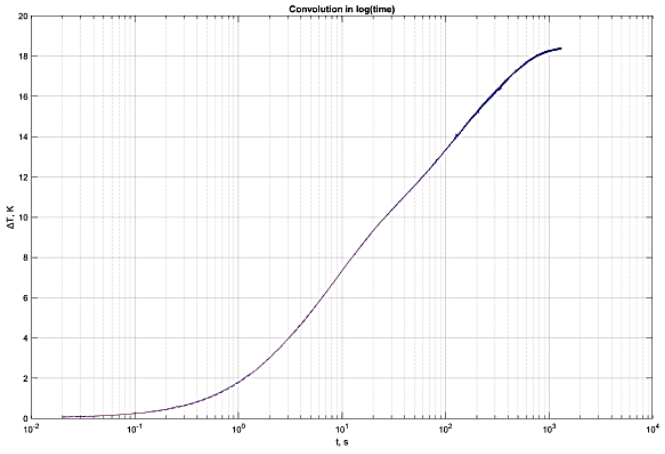

b)

Fig. 7: Overplayed temperature curves from experiment and modelling for a) weak and b) deep cooling

The expected result concerning the time constants distribution is presented in fig. 8 and in table 1. All time constants of the Foster network model are lower for deeper cooling. It means that the thermal reaction of the tissue is faster for deep thermal provocation in comparison to weak cooling. It confirms the increase of perfusion of the skin with stronger thermal stress.
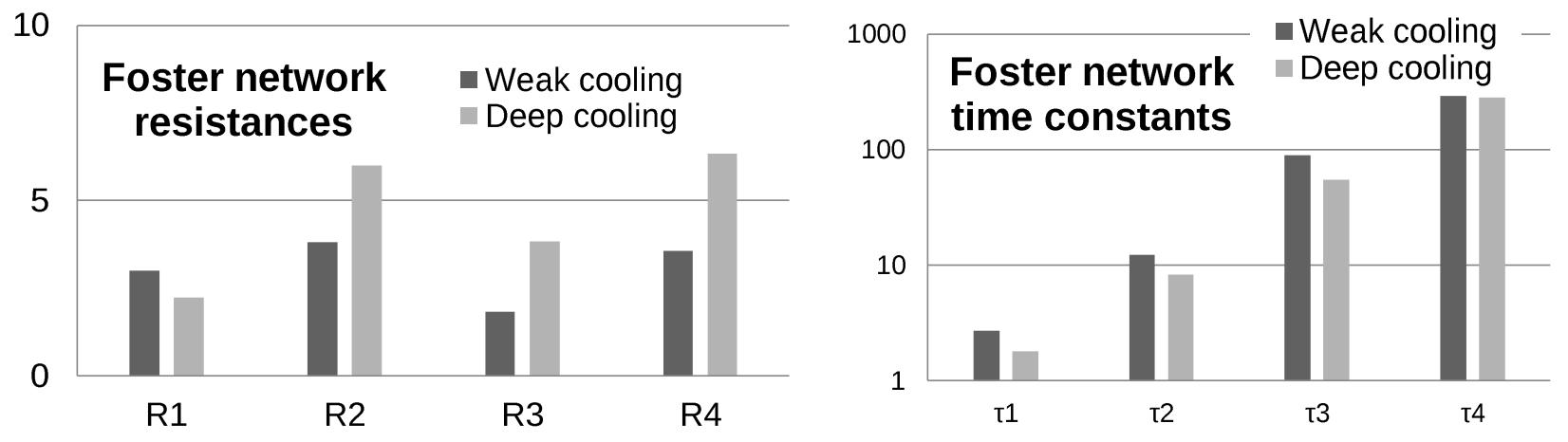

Fig. 8: Parameters of Foster network for 2 regions of the skin with weak (black bars) and deep cooling (grey bars) 




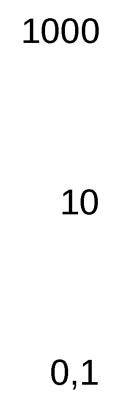

Weak cooling Deep cooling

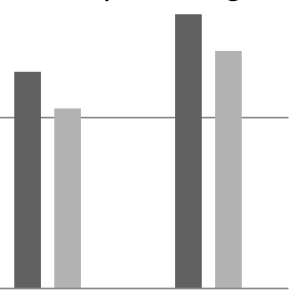

$\mathrm{C} 3$
$\mathrm{C} 4$

Fig. 9: Parameters of Cauer network for 2 regions of the skin with weak (black bars) and deep cooling (grey bars)

In addition, the Cauer network was calculated in order to get the thermal system which is physically interpretable - fig. 9 and table 2. As the skin tissue is the multilayer structure, the $R$-C Cauer network corresponds directly to the thermal parameters of the layers.

Table 1. Parameters of the Foster approximation of the thermal multilayer structure of the skin tissue

\begin{tabular}{|l|l|l|l|}
\hline \multicolumn{2}{|c|}{ Weak cooling } & \multicolumn{2}{c|}{ Deep cooling } \\
\hline$R_{1}=3,002 \mathrm{~K} / \mathrm{W}$ & $\tau_{1}=2,698 \mathrm{~s}$ & $R_{1}=2,238 \mathrm{~K} / \mathrm{W}$ & $\tau_{1}=1,789 \mathrm{~s}$ \\
\hline$R_{2}=3,805 \mathrm{~K} / \mathrm{W}$ & $\tau_{2}=12,33 \mathrm{~s}$ & $R_{2}=6,013 \mathrm{~K} / \mathrm{W}$ & $\tau_{2}=8,236 \mathrm{~s}$ \\
\hline$R_{3}=1,837 \mathrm{~K} / \mathrm{W}$ & $\tau_{3}=89,561 \mathrm{~s}$ & $R_{3}=3,827 \mathrm{~K} / \mathrm{W}$ & $\tau_{3}=55,20 \mathrm{~s}$ \\
\hline$R_{4}=3,575 \mathrm{~K} / \mathrm{W}$ & $\tau_{4}=291,802 \mathrm{~s}$ & $R_{4}=6,346 \mathrm{~K} / \mathrm{W}$ & $\tau_{4}=283,99 \mathrm{~s}$ \\
\hline
\end{tabular}

Table 2. Parameters of the Cauer approximation of the thermal multilayer structure of the skin tissue

\begin{tabular}{|l|l|l|l|}
\hline \multicolumn{2}{|c|}{ Weak cooling } & \multicolumn{2}{c|}{ Deep cooling } \\
\hline$R_{1}=5,444 \mathrm{~K} / \mathrm{W}$ & $C_{1}=0,483 \mathrm{~J} / \mathrm{K}$ & $R_{1}=4,830 \mathrm{~K} / \mathrm{W}$ & $C_{1}=0,688 \mathrm{~J} / \mathrm{K}$ \\
\hline$R_{1}=4,584 \mathrm{~K} / \mathrm{W}$ & $C_{1}=1,434 \mathrm{~J} / \mathrm{K}$ & $R_{2}=2,935 \mathrm{~K} / \mathrm{W}$ & $C_{2}=3,919 \mathrm{~J} / \mathrm{K}$ \\
\hline$R_{1}=4,865 \mathrm{~K} / \mathrm{W}$ & $C_{1}=12,875 \mathrm{~J} / \mathrm{K}$ & $R_{3}=3,202 \mathrm{~K} / \mathrm{W}$ & $C_{3}=34,86 \mathrm{~J} / \mathrm{K}$ \\
\hline$R_{1}=3,5301 \mathrm{~K} / \mathrm{W}$ & $C_{1}=60,516 \mathrm{~J} / \mathrm{K}$ & $R_{4}=1,251 \mathrm{~K} / \mathrm{W}$ & $C_{4}=162,94 \mathrm{~J} / \mathrm{K}$ \\
\hline
\end{tabular}

\section{Fitting the feedback loop model of thermoregulation to the experimental data}

The next step of the research was to model quantitatively the thermoregulation effect in a tissue and estimate the value of feedback coefficient $\beta$ for the TFM model presented in fig. 1. Two approaches were tested. In all cases, the thermal impedance obtained from the weak cooling experiment was transformed into the thermal impedance of deep cooling by closing the linear feedback and estimating the coefficient $\beta$. First, the optimization was used to calculate simultaneously the coefficient $\beta$ and the thermal resistances of Foster ladder chain $R_{i}$. The result is shown in fig. 10. As one can see, the fitting of the Nyquist plots obtained for weak and deep cooling experiment after the optimisation was not precise with the mean error $M S E=0.026 \mathrm{~K} / \mathrm{W}$. In this case $\beta=0.015 \mathrm{~W} / \mathrm{K}-\mathrm{fig} .10$. 
10.21611/qirt.2018.p34

14 $4^{\text {th }}$ Quantitative InfraRed Thermography Conference, 25 - 29 June 2018, Berlin, Germany

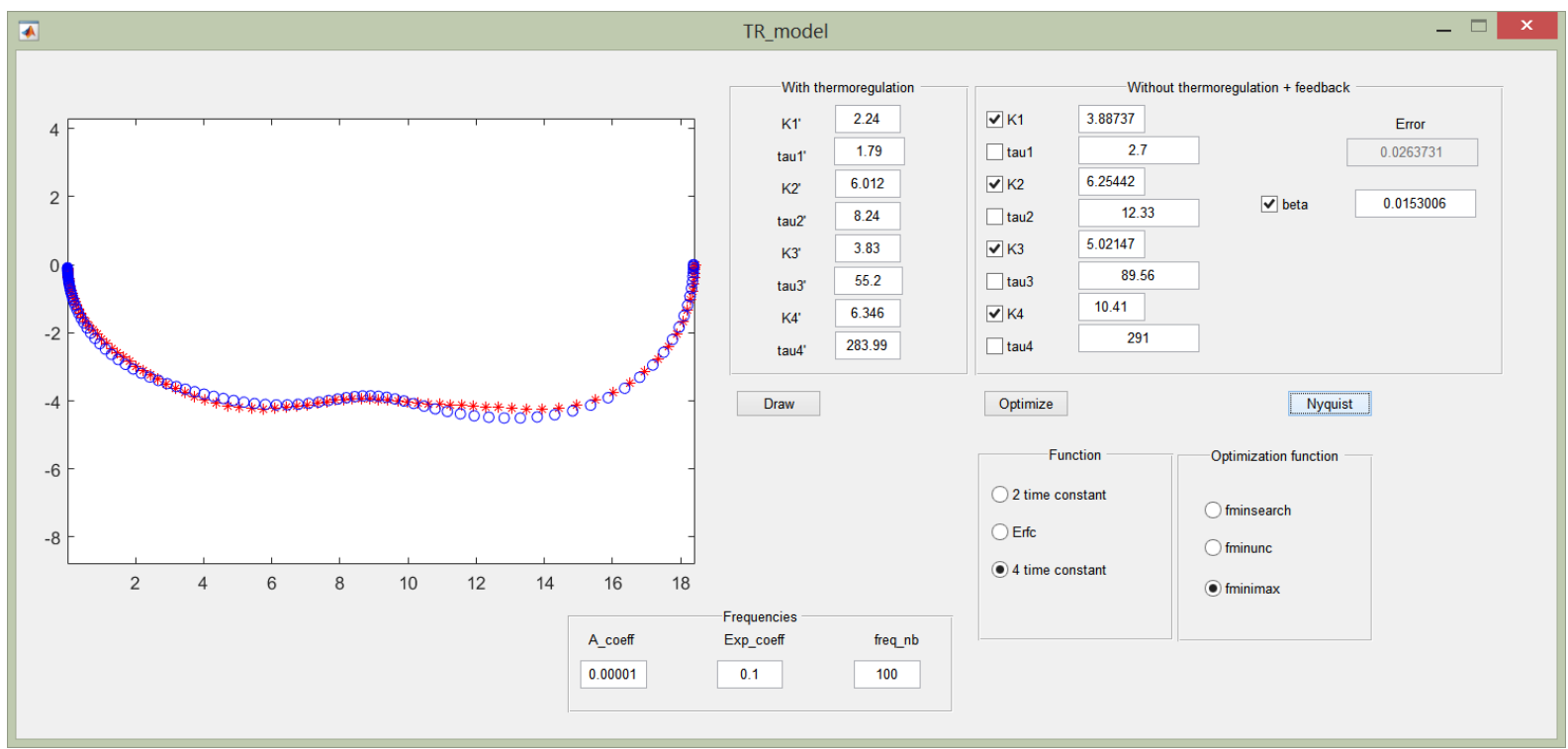

Fig. 10: Fitting the Nyquist plots from the experiment and simulation by changing feedback coefficient $\beta$ and resistances of Forster $R-C$ network

In the next fitting, all parameters of the weakly cooled model were free to change. In this case the fitting was much better with the error $M S E=2.5 \times 10^{-8} \mathrm{~K} / \mathrm{W}$. Feedback coefficient $\beta$ was estimated at $0.02 \mathrm{~W} / \mathrm{K}-$ fig. 11 . As one can notice from both above experiments, the transform from week to deep cooling cannot be modelled precisely by adjusting the value of the feedback coefficient $\beta$, only. It denotes that the thermal system of a tissue including thermoregulation is not linear. In the first approximation, especially for week thermal excitations, the thermoregulation can be analysed using the linear feedback theory. More accurate analysis needs the more advanced techniques.

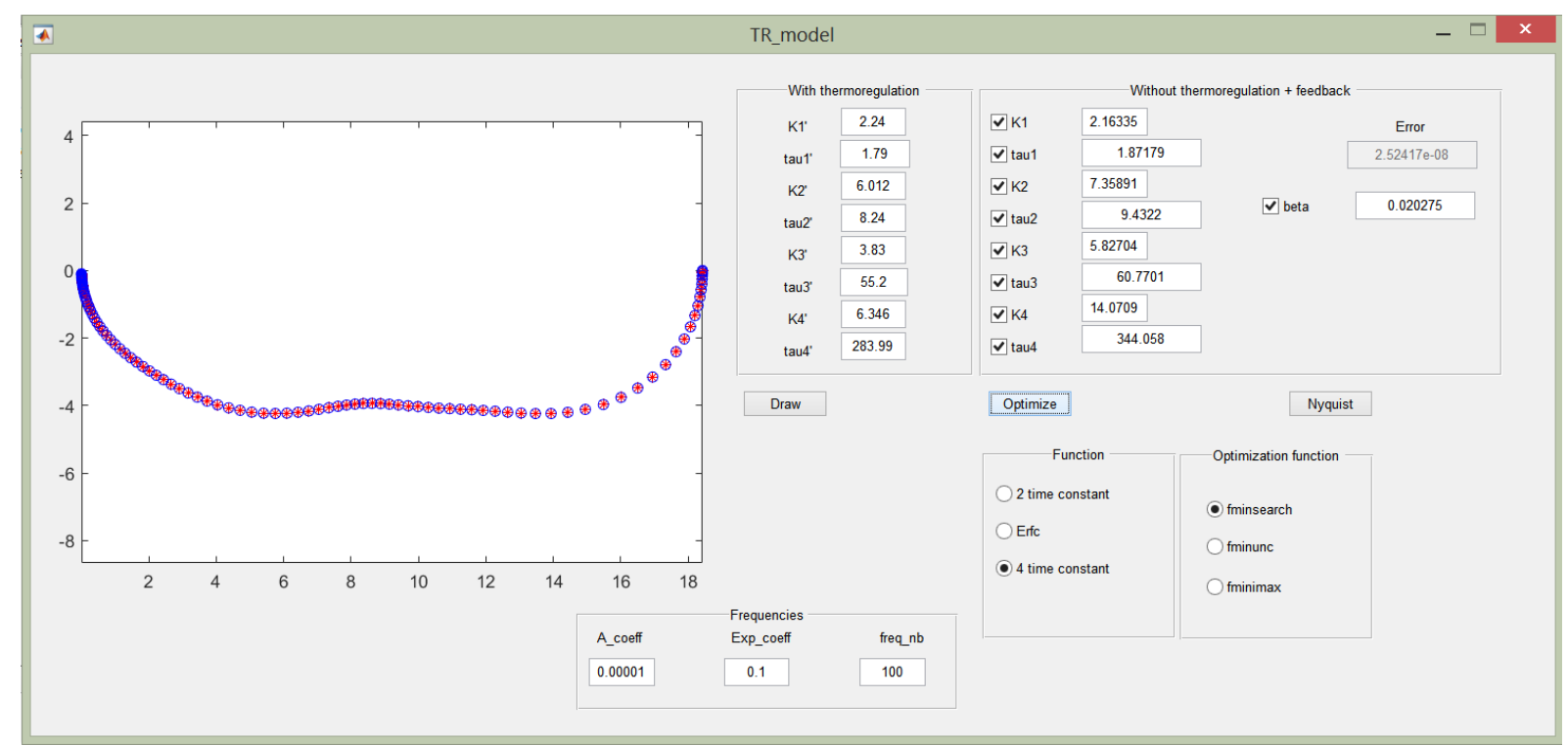

Fig. 11: Fitting the Nyquist plots from the experiment and simulation by changing feedback coefficient $\beta$ and all parameters of Forster $R-C$ network 
At the final stage of this research, the comparison of TFM and the inverse heat transfer model based on the Pennes equation was made. It allowed confirmation that the level of the negative feedback corresponds to the perfusion coefficient from the Pennes model of the human skin. The increase of perfusion coefficient refers to the value of the feedback coefficient $\beta$. The recently developed methodology of solving inverse thermal problems in bioengineering allows estimating the perfusion coefficient of a tissue [14]. The comparison of the feedback coefficient $\beta$ and the increase of perfusion coefficient $\Delta \omega$ is presented in table 3 .

Table 3. Comparison of the feedback coefficient $\beta$ and the increase of perfusion coefficient $\Delta \omega$

\begin{tabular}{|c|c|}
\hline Feedback coefficient $\beta$ & Perfusion coefficient $\omega$ \\
\hline $0,02 \mathrm{~W} / \mathrm{K}$ & Weak cooling: $0.000781 / \mathrm{s}$ \\
& Deep cooling: $0.001231 / \mathrm{s}$ \\
$\Delta \omega=0.000451 / \mathrm{s}$ \\
\hline
\end{tabular}

\section{Conclusions}

In this research, one proposed the simplified model of local thermoregulation effect in a skin tissue based on the linear thermal feedback system theory. It has been proven that the feedback coefficient is relevant to the change of perfusion in the widely accepted Pennes thermal model of a skin. The main conclusion was drawn as a hypothesis that for the deep thermal provocation, the physical reaction of the alive body moves from the linear towards nonlinear thermal behaviour.

\section{REFERENCES}

[1] Stolwijk J.A.J., Hardy J.D. (1966) Temperature regulation in man - A theoretical study. Pflugers Arch Gesamte Physiol Menschen Tiere 291(2): 129-162.

[2] Fiala D., Lomas K.J., Stohrer M. (1999) A computer model of human thermoregulation for a wide range of environmental conditions: the passive system. J Appl Physiol 87(5): 1957-1972.

[3] Fiala D., Lomas K., Stohrer M. (2001) Computer prediction of human thermoregulatory and temperature responses to a wide range of environmental conditions. Int J Biometeorol 45(3): 143-159.

[4] Havenith G., Individualized model of human thermoregulation for the simulation of heat stress response. Journal of Applied Physiology 90:2001, 1943 - 1954.

[5] Van Marken Lichtenbelt W.D., Frijns A.J.H., Fiala D., Janssen FEM, van Ooijen AMJ, et al. Effect of individual characteristics on a mathematical model of human thermoregulation. J Therm Biol 29(7): 2004, 577-581.

[6] Takemori T, Nakajima K, Shoji Y., The development of thermoregulatory model. J Jpn Soc Mech Eng 61: 2005, 1513-1520.

[7] Martínez N., Psikuta A., Kuklane K., Quesada J.I., de Anda R.M., et al. Validation of the thermophysiological model by Fiala for prediction of local skin temperatures. Int J Biometeorol 60(12): 2016, 1969-1982.

[8] Zolfaghari A., Maerefat M, A new simplified thermoregulatory bioheat model for evaluating thermal response of the human body to transient environment. Building and Environment, 45(10):2068-2076, 2010.

[9] Zolfaghari A, Maerefat M., Bioheat transfer, developments in heat transfer. InTech, 2011. ISBN: 978-953-307-5693. 
[10] Fiala D., Havenith G., Brode P., Kampmann B., Jendritzky G., UTCI-Fiala multimode model of human heat transfer and temperature regulation, Int. J. Biometeorol. 56 (2012) 429e441, http://dx.doi.org/10.1007/s00484-011-0424-7.

[11] Katic K., Rongling Li R., Zeiler W., Thermophysiological models and their applications: A review, Building and Environment 106 (2016) 286e300.

[12] Kobayashi Y, Tanabe S (2013) Development of JOS-2 human thermoregulation model with detailed vascular system. Building Environ 66: 1-10.

[13] Palella B.I., d’Ambrosio Alfano F.R., Riccio G., Department of Industrial Engineering (DII), University of Naples On the Evolution of Thermoregulation Models. Ergonomics International Journal, vol. 1, issue 3, 2017.

[14] Strąkowska M., Strąkowski R., Strzelecki M., De Mey G., Więcek B., Evaluation of Perfusion and Thermal Parameters of Skin Tissue Using Cold Provocation and Thermographic Measurements, Metrology and Measurement Systems, The Journal of Committee on Metrology and Scientific Instrumentation of Polish Academy of Sciences, Volume 23, Issue 3 (Sep 2016).

[15] Strąkowska M., De Mey G., Więcek B., Strzelecki M., A three layer model for the thermal impedance of the human skin: modelling and experimental measurements, Journal of Mechanics in Medicine and Biology, Vol. 15, No. 04, 1550044 (2015) Ref.: Ms. No. JMMB-D-14-00141R2.

[16] Więcek B., Strąkowska M., De Mey G., Marzec S., Wittchen W., Influence of infrared radiation on the human skin temperature - experimental data and modeling, Journal of Mechanics in Medicine and Biology, Vol. 13, No. 3 (2013), ISSN 0219-5194, World Scientific Publishing Company.

[17] Strakowska M., Chatzipanagiotou P., De Mey G., Chatziathanasiou V., Więcek B., Novel software for medical and technical Thermal Object Identification (TOI) using dynamic temperature measurements by fast IR cameras, QIRT 2018 Proc., Berlin, June 25-29, 2018, https://www.qirt2018.de/, http://qirt.gel.ulaval.ca/dynamique/index.php?idD=78. 